\title{
Factor V (Quebec): a Bleeding Diathesis Associated with a Qualitative Platelet Factor V Deficiency
}

Paula B. Tracy, Alan R. Giles, Kenneth G. Mann, Lisa L. Eide, Hugh Hoogendoorn, and George E. Rivard Hematology Research Section, Mayo Clinic, Rochester, Minnesota 55905; Departments of Pathology and Medicine, Queen's University and Kingston General Hospital, Kingston, Onario, Canada, Division of Hematology/Oncology, Hospital Ste. Justine, Montreal, Quebec, Canada

bstract. Studies were performed on a FrenchCanadian family afflicted with a bleeding disorder exhibiting an autosomal dominant inheritance pattern and a severe bleeding diathesis after trauma. Clinical laboratory coagulation tests were unimpressive; the only persistent abnormalities include mild thrombocytopenia and moderately reduced Factor $\mathrm{V}$ clotting activities. Some individuals had prolonged Stypven times when platelet-rich plasma was used, suggesting that their platelets could not support functional prothrombinase complex assembly. Detailed studies were performed by use of plasma and isolated, washed platelets from a sister and brother. Bioassay data indicate that both individuals had Factor $V$ activities of $\sim 40$ and $36 \%$ of normal, respectively. A comparison of the Factor $\mathrm{V}$ radioimmunoassay and bioassay data on the brother's plasma indicated that the circulating amount of Factor $V$ functional activity was low relative to Factor $\mathrm{V}$ antigen concentration $(\sim 65-75 \%)$. In both individuals, the platelet Factor $\mathrm{V}$ functional activities were extremely low $(2-4 \%)$ relative to antigen levels present as determined by radioimmunoassay. These discrepancies between Factor $\mathrm{V}$ activities and antigen concentration do

This work was presented in part at the Ninth International Meeting of the International Society of Thrombosis and Hemostasis, Stockholm, July 1983.

Address reprint requests to Dr. Tracy, whose current address is Department of Pathology, Laboratory Medicine Division, University of Rochester Medical Center, Rochester, NY.

Received for publication 21 November 1983 and in revised form 27 June 1984.

J. Clin. Invest.

(c) The American Society for Clinical Investigation, Inc.

$0021-9738 / 84 / 10 / 1221 / 08 \quad \$ 1.00$

Volume 74, October 1984, 1221-1228 not appear to be due to an unstable Factor $\mathrm{V}$ molecule or to the presence of a Factor $\mathrm{V}$ or Factor $\mathrm{Va}$ inhibitor or inactivator. Kinetics of prothrombin activation by use of purified clotting factors indicated that thrombinactivated platelets from both individuals supported prothrombinase complex assembly identical to controls in the presence of added purified Factor Va. Consequently, their bleeding diathesis appears to reflect their platelet, rather than their plasma, Factor $\mathrm{V}$ activity. These results suggest that platelet Factor $V$ is an essential component in maintaining stable and prolonged hemostasis after trauma.

\section{Introduction}

The coagulation protein, Factor $\mathrm{Va}$, is an essential cofactor for the Factor Xa-catalyzed activation of prothrombin to the clotting enzyme thrombin (1). Factor Va fulfills its cofactor role by forming the receptor for the serine protease Factor Xa at the platelet surface $(2,3)$ or, as in model systems, an equivalent phospholipid surface (4). This membrane-bound complex of Factor $\mathrm{Va}$ and Factor $\mathrm{Xa}$, plus $\mathrm{Ca}^{2+}$, constitutes the enzymatic complex prothrombinase, the terminal complex in the coagulation cascade $(1,5,6)$. The complete prothrombinase complex catalyzes thrombin formation at 300,000 times the rate achieved with Factor Xa alone $(4,7)$. The deletion of Factor Va from the complex reduces the rate of thrombin generation by four orders of magnitude (4). In view of the pivotal role of platelets in the primary events of hemostasis, this observation, relative to the enormous amplification of the thrombin-generating potential of Factor Xa after complex formation on the platelet membrane $(4,7)$, presents a logical account of the specificity, economy, and efficiency of the normal hemostatic mechanism.

Given the essential role of Factor $\mathrm{Va}$ as a cofactor in the assembly of the prothrombinase complex (4), it is perhaps not surprising that congenital Factor $\mathrm{V}$ deficiency is a rare disorder 
of hemostasis (8). In relation to congenital Factor $\mathrm{V}$ deficiency, Miletich and co-workers (9) have suggested that it is the propensity of the patient's platelets to bind Factor $\mathrm{Xa}$, rather than the circulating plasma Factor $\mathrm{V}$ level, that correlates best with the severity of the bleeding diathesis. In this report, we present information obtained from studies performed on a large French-Canadian family afflicted with a severe bleeding disorder which appears to demonstrate the essential requirement for platelet-associated Factor $\mathrm{V}$ in maintaining normal hemostasis.

\section{Methods}

Materials. Human Factor $\mathrm{V}$ was purified by use of a hybridoma antibody immonoaffinity resin as described by Katzmann et al. (10). Factor Va was prepared by incubation of Factor $\mathrm{V}$ with catalytic amounts of thrombin as described previously (11). Human prothrombin and Factor $X$ were prepared as described by Bajaj et al. (12). Factor $\mathrm{Xa}$ was prepared by a modification of the method of Downing et al. (13) by the use of Factor $X$ activator from Russell's viper venom immobilized on CNBr-activated agarose. Purified RVV-X was generously provided by Dr. Walter Kisiel (University of Washington, Seattle) (14). Bovine thrombin was prepared as described by Lundblad et al. (15).

Bovine serum albumin (recrystallized) was obtained from Pentex Biochemical (Kankakee, IL). The thrombin inhibitor, dansylarginine $N$-(3-ethyl-1,5-pentanediyl)amide (DAPA) ${ }^{1}$ was prepared as described by Nesheim et al. (16). Purified apyrase (17) was the generous gift of Dr. R. Kinlough-Rathbone (McMaster University Medical Centre, Hamilton, Ontario). All other reagents and chemicals were of analytical grade or the highest purity available.

Platelets were isolated and washed to remove plasma by strict adherence to the method of Mustard et al. (17). After the collection of blood (six parts) into acid-citrate dextrose anticoagulant (one part), all manipulations were performed at $37^{\circ} \mathrm{C}$. Platelet-rich plasma was obtained by centrifugation of the anticoagulated blood at $190 \mathrm{~g}$ for 15 min. Washed platelets were obtained by use of an albumin (0.35\%)/ Tyrode's solution containing apyrase throughout and heparin in the initial wash. After the final wash and centrifugation, the platelets were resuspended in Tyrode's wash medium $(0.137 \mathrm{M} \mathrm{NaCl}, 2.7 \mathrm{mM} \mathrm{KCL}$, $12 \mathrm{mM} \mathrm{NaHCO}_{3}, 0.36 \mathrm{mM} \mathrm{NaH}_{2} \mathrm{PO}_{4}, 1 \mathrm{mM} \mathrm{MgCl}, 5 \mathrm{mM}$ dextrose) containing $5 \mathrm{mM}$ Hepes and $3 \mu \mathrm{g} / \mathrm{ml}$ apyrase, $\mathrm{pH} 7.35$. The platelet count in the final suspension varied from 4 to $8 \times 10^{8}$ platelets $/ \mathrm{ml}$ as determined by cell counts with a Coulter counter (Coulter Electronics Inc., Hialeah, FL). Platelets to be used in the human Factor V radioimmunoassay described below were prepared in the same manner.

Coagulation assays. Blood for coagulation assays was drawn by venipuncture with a 21-gauge butterfly needle (Abbott Laboratories Ltd., Ireland Sligo, Ireland) by a two-syringe (plastic) technique. The blood was anticoagulated with sodium citrate $(3.8 \% \mathrm{wt} / \mathrm{vol})$ with 9 vol of blood to $1 \mathrm{vol}$ of anticoagulant. Platelet-poor plasma was separated immediately by centrifugation at $22^{\circ} \mathrm{C}$ at $2,500 \mathrm{~g}$ for $15 \mathrm{~min}$. For the most part, all coagulation assays were performed immediately. This was always the case for the Factor $\mathrm{V}$ assays (see below). Some of the

1. Abbreviations used in this paper: DAPA, dansylarginine $N$-(3-ethyl1,5-pentanediyl)amide; FFP, fresh-frozen plasma; RIA, radioimmunoassay. other factor assays were performed on plasma that had been snap frozen and stored at $-70^{\circ} \mathrm{C}$. Factor VIII:C, IX, XI, and XII assays were performed by use of a one-stage activated partial thromboplastin time system (18) and a normal pool plasma (obtained from 40 normal individuals) as a reference standard. With the exception of the Factor $\mathrm{V}$ assay (see below) the substrate plasmas used were obtained from severely affected individuals with congenital deficiency of the appropriate clotting factor. Factor XIII was assayed by urea solubility and antigen determination. The prothrombin time and activated partial thromboplastin time were performed on a Coag-A-Mate from General Diagnostics (Div. of Warner Lambert Co., Morris Plains, NJ) by the use of their reagents. The thrombin clot time was measured with a fibrometer (BBL Microbiology Systems, Becton Dickinson \& Co., Cockeysville, MD) according to the method of Fletcher (19). Standard methods were employed for the determination of Factor VIII:RAg (20) and Factor VIII ristocetin cofactor activity (21). Factor VIII crossed immunoelectrophoresis was performed with rabbit antihuman Factor VIII polyclonal antibodies by standard methods (22). The bleeding time was determined by Simplate (General Diagnostics, Div. of Warner Lambert). In our laboratory (A. Giles), a bleeding time $\leq 6.5 \mathrm{~min}$ is considered to be definitely normal and $\geq 9.5$ min definitely abnormal. Some normal and some abnormal individuals have bleeding times in the intervening range (23).

Platelet aggregation studies. Blood for platelet studies was obtained as described above. Platelet aggregation studies were performed using platelet-poor plasma and ADP, epinephrine, and collagen (bovine achilles tendon, Type I insoluble; Sigma Chemical Co., St. Louis, MO) as aggregating agents in an Payton Aggregometer (Payton Associates Inc., Toronto).

Bioassay of Factor $V$. Factor $\mathrm{V}$ activities were determined on plasma and washed platelet lysates by the use of Factor V-deficient plasma prepared by immunodepletion of human plasma with a murine monoclonal antihuman Factor $\mathrm{V}$ antibody coupled to Sepharose (24, $25)$. The Factor $\mathrm{V}$ immunodepleted plasma had $<0.1 \%$ detectable Factor $\mathrm{V}$ as determined by both radioimmunoassay (RIA) (25) and clotting activity. A two-stage clotting assay was used in which Factor $\mathrm{V}$ was converted to Factor Va by thrombin and then assayed for activity as described previously $(24,26)$. In each case, the bioassay results were standardized against highly purified human Factor $V$. After thrombin activation, our purified human Factor $\mathrm{V}$ preparations express clotting activities of $\sim 1,700 \mathrm{U} / \mathrm{mg}$ of protein when based on an unactivated bovine plasma standard (35 $\mu \mathrm{g}$ Factor $\mathrm{V} / \mathrm{ml}$ plasma [24]) or $\sim 8,500 \mathrm{U} / \mathrm{mg}$ of protein when based on an unactivated human plasma standard (7 $\mu \mathrm{g}$ Factor $\mathrm{V} / \mathrm{ml}$ of plasma [25]). Platelet lysates were prepared from a known concentration of washed platelets (typically $2.5 \times 10^{8}$ platelets $/ \mathrm{ml}$ ) by the addition of Triton X-100 (final concentration, $0.2 \%$ ).

RIA of plasma and platelet Factor $V$. Plasma and platelet concentrations of Factor $\mathrm{V}$ were determined by a double-antibody competition RIA as previously described (25) in which highly purified human Factor $\mathrm{V}$ was used for construction of the standard curve.

Kinetics of prothrombin activation monitored with DAPA. Kinetics of prothrombin activation were used $(a)$ to determine the ability of the patients' platelets to participate in prothrombinase complex assembly and to provide the cofactor Factor $\mathrm{Va}$, and $(b)$ to determine the apparent dissociation constant $\left(K_{d}\right)$ and maximum rate of prothrombin activation governing prothrombinase complex assembly and function on the patients' platelets. The time course of thrombin generation, observed as enhanced DAPA fluorescence intensity, was continuously recorded as described previously by Nesheim et al. $(4,24)$. Prothrombin 
activations were performed at ambient temperature in Tyrode's platelet wash medium (see Methods) containing $5 \mathrm{mM}$ Hepes, pH 7.35 Reaction mixtures contained $1.39 \mu \mathrm{M}$ prothrombin, $2.0 \mathrm{mM} \mathrm{Ca}{ }^{2+}, 3$ $\mu \mathrm{M}$ DAPA, and thrombin-activated platelets $\left(1 \times 10^{8} / \mathrm{ml}\right)$. Platelets were thrombin-activated $(0.5 \mathrm{U} / \mathrm{ml}, 2 \mathrm{~min})$ immediately before the addition of the remaining reagents. Prothrombin activations were initiated by the addition of Factor $\mathrm{Xa}$. The assays were performed both with and without added Factor Va, and in each case the patient's platelets were compared with controls. In the absence of added Factor $\mathrm{Va}, 5.0 \mathrm{nM}$ Factor $\mathrm{Xa}$ was added, a saturating concentration with respect to thrombin formation, in order to reflect the Factor Va being supplied by the patient's or control platelets. In the presence of added Factor $\mathrm{Va}$, reaction conditions were established such that isolated Factor Va was added at a concentration that was saturating with respect to the rate of thrombin generation, and the amount of Factor $\mathrm{Xa}$ was varied in order to determine the kinetic and binding parameters governing the Factor Xa-platelet interaction as previously described $(2,27,28)$.

Case report. Fig. 1 shows the pedigree of the family studied. Two members of the fourth generation (IV.13 and IV.15) have been studied in detail and are the subject of this report. Predominantly historical data demonstrate a disorder of hemostasis with an autosomal dominant inheritance pattern. Clinically, this is characterized by moderate to severe bleeding after trauma, particularly dental extraction or tonsillectomy. The hemorrhagic tendency is present from birth, with a number of affected family members bleeding from the umbilical stump. One individual (II.2) is known to have died as a result of uncontrollable hemorrhage. A number of other individuals have required major blood transfusion after relatively trivial surgical procedures. No blood product has been found to correct predictably the bleeding tendency. Fibrinolytic inhibitors have often been found to help in controlling hemorrhage.

The two individuals studied in detail were a stepbrother and a sister. Individual IV.15 (age $32 \mathrm{yr}$ ) has a significant history of bleeding. At the age of six she bled for a week after the loss of a primary tooth.
At the age of seven she bled from a superficial scalp wound for $>8$ wk. At the age of 10, she bled intermittently for 6 mo from a deep laceration to her foot. Before puberty, she bruised easily, but this is no longer a feature of her condition. At the age of 16 , she had a major bleed after dental extraction, and this occurred again after a similar procedure at the age of 25 . Transfusion of platelets, plasma, and cryoprecipitate did not appear to ameliorate the bleeding tendency. Menstrual bleeding was intermittently associated with major blood loss, which appears to be controlled by subsequent therapy with the oral contraceptive pill. Her first pregnancy was complicated by a postpartum hemorrhage; however, her second and third pregnancies were uneventful. Laboratory investigation demonstrated a persistent, mild thrombocytopenia (110-126 $\times 10^{9}$ /liter), a moderately reduced Factor V activity (30-40\%), abnormal clot retraction, and abnormal Stypven time (29) when platelet-rich plasma but not platelet-poor plasma was used, and occasional minimal prolongation of the prothrombin time. All other tests, including activated partial thromboplastin time, thrombin clotting time, Factor VIII studies that included crossed immunoelectrophoresis, Factor XIII, platelet aggregation and sizing studies, and bone marrow examination were within normal limits.

Individual IV.13 [age $22 \mathrm{yr}$ ] has a history of bleeding similar to that of his sister. At the age of $19 \mathrm{mo}$, he bled for $2 \mathrm{wk}$ after biting his tongue. At the age of $21 \mathrm{mo}$, he bled for $5 \mathrm{~d}$ after biting his lower lip. No specific treatment was instituted for either of these episodes. At the age of five, two upper incisors were extracted. Initially, no abnormal bleeding was noted, but oozing began $12 \mathrm{~h}$ postextraction and continued for $6 \mathrm{~d}$. Initially, fresh-frozen plasma (FFP) was administered at a dose of $10 \mathrm{ml} / \mathrm{kg}$ body wt every $8 \mathrm{~h}$ for $3 \mathrm{~d}$. No beneficial effect was noted, and bleeding ceased spontaneously $3 \mathrm{~d}$ after FFP was stopped. At age nine, abnormal bleeding occurred $3 \mathrm{~h}$ postextraction of two upper molars. Again, the initial hemostatic response appeared to be normal. This was despite prophylactic administration of FFP at a dose of $10 \mathrm{ml} / \mathrm{kg}$ body wt every $8 \mathrm{~h}$. FFP was continued for $6 \mathrm{~d}$ without any noticeable effect, the hemoglobin level falling from 12.5

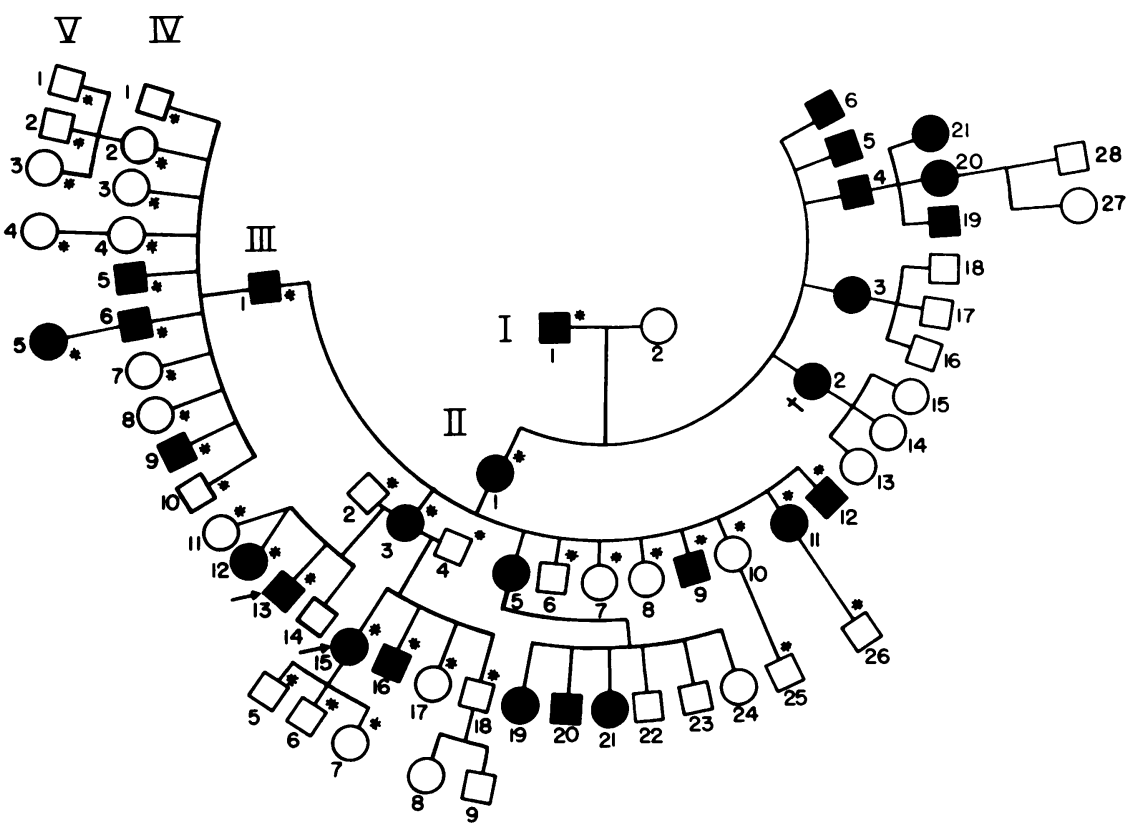

Figure 1. Pedigree of Factor V Quebec. Solid symbols, symptomatic (history). Open symbols, nonsymptomatic (history). ${ }^{*}$ Lab data available. $\nmid$ Died postpartum bleeding. $\nearrow$, Proband. 
to $6.5 \mathrm{~g} \%$. Bleeding eventually stopped spontaneously $3 \mathrm{~d}$ after FFP administration had been terminated. At the age of 10 , his lacerated finger was sutured, but bleeding resulted in delayed healing and continued for 2 to $3 \mathrm{wk}$. No specific treatment was administered. At the age of 15 he developed a spontaneous hematoma of the left paranasal and upper gingival region associated with the eruption of a wisdom tooth. FFP at a dose of $10 \mathrm{ml} / \mathrm{kg}$ every $12 \mathrm{~h}$ and predisone, 1 $\mathrm{mg} / \mathrm{kg}$, were without effect. Epsilon aminocaproic acid (Amicar, Lederle Laboratories, Div. of American Cyanamid, Wayne, NJ) was then begun at a dose of $100 \mathrm{mg} / \mathrm{kg}$ every $6 \mathrm{~h}$. After $8 \mathrm{~d}$ of treatment, the hematoma regressed. Between the ages of 17 and 22, he exhibited numerous spontaneous hemathroses of the ankles. These were treated with bedrest, with or without FFP administration. Again, the administration of FFP did not appear to be of any significant benefit. Hemathrosis has not been a feature of his sister's clinical course but had been documented in four other male (III.9, III.12, IV.5, and IV.6) and two female (II.1 and III.11) members of the family. During $20 \mathrm{yr}$ of follow-up at the same institution, regular platelet counts have varied in the range $125-140 \times 10^{9}$ per liter. Similarly, regular screening tests of coagulation function, i.e., prothrombin time and activated partial thromboplastin time, have been found to be within the normal range. Minimal prolongation of the bleeding time has been observed intermittently. Similar to that of his sister, his Factor $\mathrm{V}$ activity was moderately reduced in the $\mathbf{4 0}$ to $50 \%$ range. All of the tests, including Factor VIII, Factor XIII, platelet aggregation and sizing studies, and bone marrow examinations were within normal limits. Platelet morphology by light and electron microscopy was normal as were total platelet nucleotides, measured by firefly and high-pressure liquid chromatography methods.

The association of a mild thrombocytopenia and moderate reduction in Factor $\mathbf{V}$ activity has been found in all affected family members who have been studied. The bleeding time in these patients is either normal or marginally prolonged in any one individual. All other coagulation tests and platelet function studies are within normal limits.

\section{Results}

At the time of these studies, both patients had normal prothrombin time, activated partial thromboplastin time, and thrombin clot time. All factor assays, except for Factor V (see below), were within the normal range. The platelet count of both patients varied within the range $125-140 \times 10^{9} /$ liter. The bleeding time measurements of the brother (IV.13) were always normal; i.e., $<6.5 \mathrm{~min}$. In the case of the sister (IV.15), it was normal on one occasion and marginally prolonged on the second $(9 \mathrm{~min})$. The sister remained on the oral contraceptive pill during the studies performed.

Plasma Factor $V$ concentrations. Both patients' plasma Factor V concentrations were measured by RIA and bioassay as shown in Table I. Bioassay data demonstrated a mild reduction in Factor $\mathrm{V}$ activities in both the brother and sister, 36 and $40 \%$ of normal, respectively (25). There was also a mild reduction in the Factor $\mathrm{V}$ antigen in both patients. This was somewhat less than that determined by bioassay. In the case of the sister, it appeared that $88 \%$ of her plasma Factor $\mathrm{V}$ antigen was functionally active, whereas with the brother, assayed on two separate occasions, 66 and $76 \%$ of his plasma Factor $\mathrm{V}$ antigen appeared to be functional.
Table I. Plasma Factor V Concentrations

\begin{tabular}{llll}
\hline & $\begin{array}{l}\text { Factor V antigen } \\
\text { RIA }\end{array}$ & $\begin{array}{l}\text { Factor V activity } \\
\text { bioassay* }\end{array}$ & $\begin{array}{l}\text { \% Active Factor V } \\
\text { bioassay/RIA }\end{array}$ \\
\hline & $\mu g / m l$ & $\mu g / m l$ & \\
IV.15 (\$) & 3.4 & 3.0 & 88 \\
IV.13 (§) & 4.1 & 2.7 & 66 \\
& 5.8 & 4.4 & 76 \\
Normal & $6.8 \pm 2.0$ & $7.5 \pm 1.7$ & $110 \pm 9$ \\
\hline
\end{tabular}

* Bioassay data were standardized (micrograms per milliliter) against a highly purified human Factor $\mathrm{V}$ preparation $(1,700 \mathrm{U} / \mathrm{mg}$ of protein).

$\ddagger$ Mean $\pm S D$ of 22 normal individuals whose plasma factor $V$ antigen was determined by RIA and bioassay. The ratio of antigen determined by each assay was calculated for each individual (25).

Our previous studies (25) indicate that $>100 \%$ of the normal plasma Factor $\mathrm{V}$ antigen determined by RIA is thrombin-activatable and functional as determined by bioassay (Table I). In no individual $(n=22)$ did we observe less Factor $V$ functional activity than the antigen determination predicted. The discrepancy observed between the Factor $\mathrm{V}$ antigen and activity measurements obtained with both patients suggests the presence of a pool of a functionally abnormal Factor $V$ protein that will not express Factor Va activity after intentional activation by thrombin. However, the difference between Factor $\mathrm{V}$ antigen and the functional activity expressed is an unlikely explanation for the severity of the clinical symptoms observed in each patient.

Characterization of platelet-associated Factor $V$. Platelets from both patients were washed for use in the Factor V RIA as described in Methods. In the final suspension, the platelets were diluted with platelet wash medium to $2.5 \times 10^{8}$ platelets/ $\mathrm{ml}$ as determined by cell counts with a Coulter counter and then lysed by the addition of $10 \%$ Triton X-100 (final concentration of $0.2 \%$ ). Factor $\mathrm{V}$ activities were determined on the platelet lysates by bioassay and compared with Factor $V$ antigen levels determined by RIA. The results obtained are shown in Table II and compared with normal control data

Table II. Platelet Factor V Concentrations (Molecules Factor V/Platelet)

\begin{tabular}{llll}
\hline & $\begin{array}{l}\text { Factor V antigen } \\
\text { RIA }\end{array}$ & $\begin{array}{l}\text { Factor V activity } \\
\text { bioassay* }\end{array}$ & $\begin{array}{l}\text { \% Active Factor V } \\
\text { bioassay/RIA }\end{array}$ \\
\hline IV.15 (\$) & 2,908 & 126 & 4 \\
IV.13 (8) & 5,558 & 122 & 2 \\
& 7,260 & 157 & 2 \\
Normal‡ & $7,980 \pm 2,885$ & $6,750 \pm 2,870$ & $83 \pm 10$ \\
\end{tabular}

* Bioassay data were standardized (micrograms per milliliter) against a highly purified human Factor $\mathrm{V}$ preparation $(1,700 \mathrm{U} / \mathrm{mg}$ of protein).

$\ddagger$ Mean \pm SD of eight normal individuals whose platelet Factor $V$ antigen was determined by both RIA and bioassay. The ratio of antigen determined by each assay was calculated for each individual (25). 
previously determined (25). A gross discrepancy was observed between the amount of platelet-associated Factor $\mathrm{V}$ determined by bioassay and RIA for both the brother and sister. In the case of the brother, assayed on two separate occasions, the RIA data indicated the presence of a normal amount of Factor $\mathrm{V}$ antigen; however, only $2 \%$ of the Factor $\mathrm{V}$ molecules expressed Factor Va activity after thrombin activation. In the case of the sister, not only was her platelet Factor $\mathrm{V}$ antigen somewhat lower than controls, but, in addition, only $4 \%$ of the Factor $\mathrm{V}$ present expressed cofactor activity. These results were verified further by Factor V bioassay and RIA determinations of the Factor $\mathrm{V}$ activity and antigen released after thrombin activation of both patients' platelets. RIA data demonstrated the release of the Factor $\mathrm{V}$ antigen present in Triton X-100 extracts of intact platelets, whereas bioassay data again demonstrated minimal functional Factor $\mathrm{V}$ activity. The Factor $\mathrm{V}$ activity could not be increased by the further addition of thrombin. These data indicate also that the two patients are not compromised by a platelet release defect. Furthermore, there is no evidence of a platelet storage pool defect based on ultrastructural studies and their nucleotide content as outlined in the case histories.

Contribution of thrombin-activated platelets to prothrombinase activity. Kinetics of prothrombin activation were monitored to determine if thrombin-stimulated platelets obtained from both patients could generate prothrombin activity in the absence or presence of added Factor Va ( $5 \mathrm{nM})$. Washed patient or control platelets $\left(1 \times 10^{8} / \mathrm{ml}\right)$ were thrombin activated and their prothrombinase activity was determined in the presence of $1.39 \mu \mathrm{M}$ prothrombin and $0.5 \mathrm{nM}$ Factor $\mathrm{Xa}$. The results obtained are shown in Table III and expressed both as the rate of thrombin produced and as a percentage of the prothrombinase activity elicited by normal control platelets

Table III. Prothrombinase Activity of Thrombin-stimulated Platelets*

\begin{tabular}{lll}
\hline & \multicolumn{2}{l}{ Rate of thrombin generation } \\
& $\begin{array}{l}\text { No added } \\
\text { Factor Va }\end{array}$ & $\begin{array}{l}\text { Factor Va } \\
\text { added }\end{array}$ \\
\hline IV.13(8) & $0.04(2.5 \%) \ddagger$ & $2.68(103 \%)$ \\
IV.15 (\&) & $0.054(3.4 \%)$ & $2.34(90 \%)$ \\
Control & $1.6(100 \%)$ & $2.6 \quad(100 \%)$ \\
\hline
\end{tabular}

\footnotetext{
* Platelets $\left(1 \times 10^{8} / \mathrm{ml}\right)$ were thrombin activated and assayed for prothrombinase activity by monitoring of the rate of thrombin generation by increased fluorescence of the DAPA-thrombin complex $(4,24)$. Prothrombin activation mixtures contained: $1 \times 10^{8}$ platelets/ml, $139 \mu \mathrm{M}$ prothrombin, $3 \mu \mathrm{M}$ DAPA, $2 \mathrm{mM} \mathrm{Ca}^{2+}$, and 0.5 $\mathrm{nM}$ Factor $\mathrm{Xa}$. When added, Factor Va was present at $5 \mathrm{nM}$. Initial velocities of thrombin formation were obtained from recorded data. $\ddagger$ Expressed as a percentage of the control rate.
}

analyzed on the same day. In the absence of any added Factor $\mathrm{Va}$, thrombin-stimulated platelets from the sister and brother elicited prothrombinase activities of only 3.4 and $2.5 \%$ of the activity generated by normal thrombin-activated platelets. The addition of a (normal) platelet receptor-saturating concentration of Factor Va $(5 \mathrm{nM})$ to the patient's platelets resulted in prothrombinase activity almost identical to that of the control normal platelets. These results suggest that the patients' platelets can participate in prothrombinase complex assembly in the presence of added clotting factors. These results suggest also that the minimal Factor Va activity released by thrombin stimulation of their platelets will function in its cofactor role, since a small amount of prothrombin activation was evident even in the absence of exogenously added Factor Va.

Additional similar experiments were performed with the brother's platelets on a separate occasion in which experiments were designed to confirm our previous results and to determine if his platelets contained either a Factor $\mathrm{V}$ or $\mathrm{Va}$ inactivator or inhibitor. Prothrombin activation mixtures contained thrombin-stimulated control or patient platelets $\left(1 \times 10^{8} / \mathrm{ml}\right)$, $1.39 \mu \mathrm{M}$ prothrombin, and $5.0 \mathrm{nM}$ Factor $\mathrm{Xa}$, a concentration that is saturating with respect to the rate of thrombin generation. Control platelets were obtained from a normal individual with no apparent hemostatic defect. These platelets contained $\sim 2,000$ molecules of Factor $\mathrm{V}$ per cell, an amount somewhat lower than our previously established normal range $(4,600$ 14,000 molecules of Factor V/platelet, [25]). The results obtained are shown in Fig. 2. Control platelets, in the absence of added Factor $\mathrm{Va}$, generated $\sim 35 \%$ of the initial rate of thrombin generation seen when saturating amounts of Factor Va ( $5 \mathrm{nM}$ ) were added. In contrast, the brother's platelets generated much less activity, $\sim 3 \%$ of that generated in the presence of saturating amounts of Factor Va. It should be noted that the patient's platelets expressed almost $10 \%$ the activity of the normal, control platelets in this experiment, in contrast to the $2-2.5 \%$ presented in Tables II and III, respectively. Since the control platelets contained less than normal amounts of platelet Factor V, we suggest that this experiment demonstrates a reasonable estimation of the maximum activity the patient's platelet Factor $\mathrm{V}$ would generate when compared with normal platelets.

A similar experiment was performed to test for the presence of a Factor $\mathrm{V}$ or $\mathrm{Va}$ inactivator or inhibitor in the patient's platelets. The supernatant, obtained from centrifugation of the brother's thrombin-activated platelets through oil, was added to the assay system reconstituted with normal control platelets. The Factor Va present in the patient's platelet supernatant $\left(\sim 0.3 \times 10^{-10} \mathrm{M}\right)$ resulted in the production of additional prothrombinase activity by the control platelets (Fig. 2). These results suggest that the patient's platelets did not release products that either inhibited or inactivated Factor Va since the ability of normal control Factor Va to participate in prothrombin activation was not compromised.

Additional studies were performed to test these possibilities 


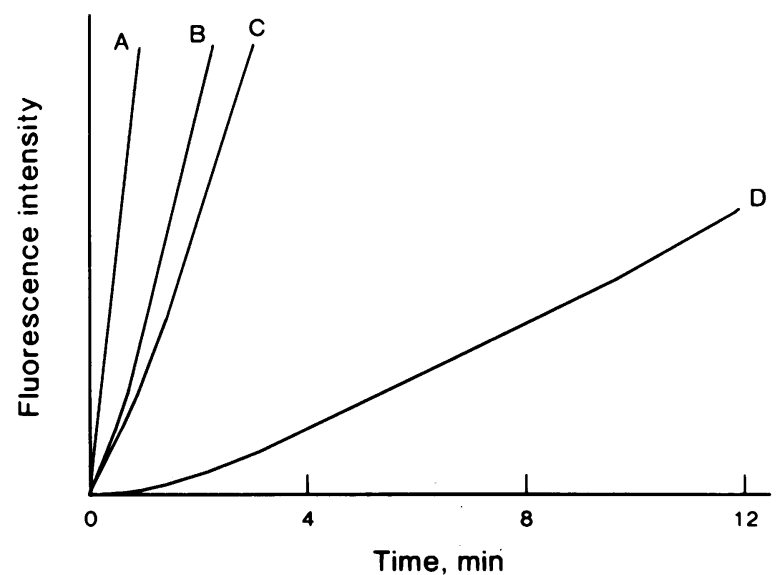

Figure 2. Contribution of thrombin-activated platelets to prothrombinase activity. Washed patient or control platelets were thrombin activated $(0.5 \mathrm{U} / \mathrm{ml}, 2 \mathrm{~min})$, and prothrombinase activity was determined by monitoring of the rate of thrombin generation by increased fluorescence of the DAPA/thrombin complex $(4,26)$ in the presence of: $1 \times 10^{8}$ platelets $/ \mathrm{ml}, 1.39 \mu \mathrm{M}$ prothrombin, $3 \mu \mathrm{M}$ DAPA, and 5 $\mathrm{nM}$ Factor $\mathrm{Xa}$. When added, Factor $\mathrm{Va}$ was present at $5 \mathrm{nM}$. The tracings represent: $(A)$ rate obtained with either patient or control platelets when exogenous Factor Va was added $(100 \%$ of the initial maximum rate); $(B)$ rate obtained when the supernatant from a patient thrombin-activated platelet suspension $\left(1 \times 10^{8}\right.$ platelets $\left./ \mathrm{ml}\right)$ was added to control platelets in the absence of added Factor Va ( $41 \%$ of initial maximum rate); $(C)$ rate obtained with control platelets in the absence of added Factor Va (35\% of initial maximum rate); and $(D)$ rate obtained with patient platelets in the absence of added Factor Va (3\% of initial maximum rate).

further. Incubation of the patient plasma or platelet lysates at $37^{\circ} \mathrm{C}$ showed no loss of intrinsic Factor $\mathrm{V}$ activity when compared with normal control plasma and platelet lysates over a 3-h period. Similarly, incubation of purified human Factor $\mathrm{V}$ or Va with patient plasma or patient platelet lysates at $37^{\circ} \mathrm{C}$ had no detrimental effects on the Factor $\mathrm{V}$ or $\mathrm{Va}$ activity when compared with the incubation of Factors $\mathrm{V}$ and $\mathrm{Va}$ in control plasma or platelet lysates. These studies exclude the possibility that the lack of platelet Factor $\mathrm{V}$ activity in the patients' platelets was a consequence of abnormal proteolytic activity or an inhibitor of either the normal procofactor or Factor Va.

Kinetic determinations of the binding interaction of Factor $X a$ with platelets. The studies outlined thus far indicate that the platelets obtained from these patients appear to be able to participate in functional prothrombinase complex assembly in the presence of added coagulation factors. To confirm that their platelet participation in prothrombinase complex assembly was similar to that of control platelets, experiments were performed in which the influence of Factor Xa on the rate of prothrombin activation was taken to reflect Factor Xa binding to platelet-bound Factor $\mathrm{Va}$ as described previously $(2,27)$. Reaction conditions were such that the concentration of Factor
Va added ( $5 \mathrm{nM}$ ) was saturating with respect to the rate of thrombin generation observed, and the amount of Factor Xa was varied in order to determine its influence on the reaction rate. Double reciprocal analysis of the rate saturation curve obtained as a function of Factor Xa added allowed calculation of the binding and kinetic parameters governing prothrombinase complex assembly. The brother, who was the more symptomatic of the two patients, was studied on two occasions. In each case, the platelets were thrombin activated immediately before the performance of each assay. The kinetic determination of the Factor Xa interaction with the brother's platelets is virtually identical to that with control platelets, as shown in Fig. 3. An apparent $K_{\mathrm{d}}$ of $1.15 \times 10^{-10} \mathrm{M}$ and maximum rate of prothrombin activation equal to $6.8 \times 10^{-7} \mathrm{M}$ thrombin/min were calculated for the patient. Analysis of the control data yielded an apparent $K_{\mathrm{d}}$ of $0.8 \times 10^{-11} \mathrm{M}$ and a maximum rate of prothrombin activation equal to $5.6 \times 10^{-7} \mathrm{M}$ thrombin/ min. If the assumption were made that purified Factor $\mathrm{Xa}$ would express the same catalytic efficiency when complexed with Factor Va bound to either the patient or control platelets, the rate saturation curves depicted in Fig. 3 could be considered to represent Factor Xa-platelet binding isotherms. Double reciprocal analyses $(2,27,28)$ of the patient data allowed calculation of $\sim 3,000$ functional Factor $\mathrm{Xa}$ binding sites on the surface of the patient's thrombin-activated platelets. Studies

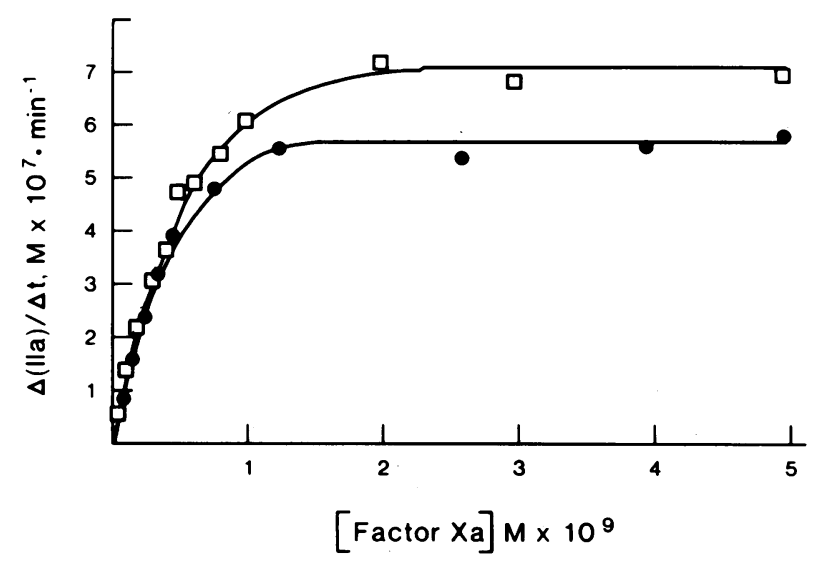

Figure 3. Factor Xa platelet-binding as monitored by the kinetics of prothrombin activation. Prothrombin activation mixtures contained $1.39 \mu \mathrm{M}$ prothrombin, $3 \mu \mathrm{M}$ DAPA, $\mathrm{i} \times 10^{8}$ thrombin-activated platelets $/ \mathrm{ml}$, and $5 \mathrm{nM}$ Factor Va. Reactions were initiated by the addition of varying concentrations of Factor $\mathrm{Xa}$, and initial velocities of thrombin formation were obtained from recorded data. Results are expressed as the amount of thrombin generated per minute as a function of nominal Factor Xa concentration for the patient ( $\square$ ) and control $(\bullet)$. Double reciprocal analyses $(2,27,28)$ of the rate saturation curves shown allowed calculation of the apparent $K_{d}$, maximum rate of prothrombin activation $\left(V_{\max }\right)$, and number of Factor $\mathrm{Xa}$ platelet binding sites: $\square$, apparent $K_{\mathrm{d}}=1.14 \times 10^{-10} \mathrm{M}, V_{\max }=6.8$ $\times 10^{-7} \mathrm{M}$ thrombin $/ \min , n=3,000 ; \bullet$, apparent $K_{\mathrm{d}}=0.81 \times 10^{-10}$ $\mathrm{M}, V_{\max }=5.6 \times 10^{-7} \mathrm{M}$ thrombin $/ \min , n=2,600$. 
in our laboratory (Drs. Tracy and Mann) have demonstrated that Factor Xa binds to $\sim 2,700 \pm 1,000(n=8)$ functional sites on the surface of normal thrombin-activated platelets with an apparent $K_{\mathrm{d}}$ equal to $1.2 \pm 0.6 \times 10^{-10} \mathrm{M}(27,28)$. It appears that the brother's platelets will bind Factors $\mathrm{Va}$ and $\mathrm{Xa}$ functionally in a manner identical to that observed for control platelets and that once they are bound, normal prothrombinase activity is expressed.

\section{Discussion}

The patients described appear to have a significant clinical disorder of hemostasis, even though the conventional clinical laboratory findings are relatively unimpressive. Although the decreased Factor $\mathrm{V}$ activities observed would not usually be considered to be reduced to a clinically significant degree, the symptoms reported were similar to those known to be associated with a severe congenital Factor $\mathrm{V}$ deficiency (8). The consistent finding of a mild reduction in plasma Factor $\mathbf{V}$ activities directed us to consider a dysfunctional Factor $\mathrm{V}$ state as an explanation for their bleeding diathesis. Since Factor V(Va) is essential to the generation of normal platelet prothrombinase activity, we studied also the ability of the patients' platelets to participate in prothrombinase complex assembly and function.

Our studies clearly demonstrate that the inherited defect appears to result from the almost complete absence of functionally active Factor $\mathrm{V}$ in the patients' platelets. Kinetics of prothrombin activation by the use of purified clotting factors indicate that the patients' platelets will support the assembly of a functional prothrombinase complex only when purified Factor $\mathrm{Va}$ is added exogenously. Consequently, their platelets could exhibit normal prothrombinase activity if their plateletassociated Factor $\mathrm{V}$ activity were normal.

In addition to what appears to be an abnormal platelet Factor $\mathrm{V}$ molecule, there is evidence that a minor fraction of the plasma Factor $\mathrm{V}$ is also dysfunctional. These observations may be explained either by different sites of synthesis of plasma- and platelet-associated Factor $\mathrm{V}$ or, alternatively, by increased import into or decreased export from platelets of a dysfunctional Factor V molecule. Should the abnormality reside in the synthesis of an abnormal Factor $\mathrm{V}$ molecule by megakaryocytes, transfusion of normal donor platelets may be expected to be of therapeutic benefit. Some patients have, in fact, received such treatment, and available clinical data indicate that platelet transfusions were not always successful in controlling hemorrhage. Consequently, questions about the stability of Factor $\mathrm{V}$ in platelet concentrates, as well as the ability of stored platelets to release Factor V, need to be addressed. Should the abnormality result from normal platelets demonstrating an increased affinity for a dysfunctional Factor $V$ molecule, it might be expected that some benefit would accrue only from the use of a Factor V concentrate with or without platelet transfusions.

To our knowledge, this is the first description of both an inherited qualitative Factor $\mathrm{V}$ disorder and the association of a significant bleeding diathesis with a predominantly platelet Factor V abnormality. Currently, no data are available on the platelet Factor V activity of individuals with Gray platelet syndrome, a rarely detected disorder since patients with the defect do not manifest severe bleeding tendencies (30). Individuals with this defect have a marked deficiency in $\alpha$-granule content and the proposed platelet storage site for Factor $\mathrm{V}$ $(31,32)$, and they exhibit a slight prolongation of their bleeding time as well as an increased susceptibility to bruising (33). Preliminary data from our laboratory (Drs. Tracy and Mann) indicate that lysed platelets from a patient with this syndrome contain near normal amounts of Factor $\mathrm{V}$ antigen $(\sim 2,600$ molecules Factor $\mathrm{V}$ per cell). However, lyophilization of the sample prevented the determination of Factor $\mathrm{V}$ activity. Vicic et al. (34) have reported that stimulated platelets from a patient with a combined dense granule and $\alpha$-granule deficiency released $\sim 50 \%$ of the Factor $\mathrm{V}$ activity released by control platelets. As this level of Factor $\mathrm{V}$ activity appears to be slightly less than the normal activity range determined previously by our laboratory, 58-177\% (4,600-14,000 molecules Factor V per platelet [25]), it is unlikely that this would account for any bleeding tendencies manifested by this individual.

The association of a severe bleeding disorder with the absence of platelet Factor $\mathrm{V}$ activity demonstrates that the platelet content of Factor $\mathrm{V}$ and its subsequent release after platelet activation is a critical determinant of the efficiency of the hemostatic process. Since it appears that there is enough Factor $\mathrm{V}$ available on the unperturbed platelet surface to provide an optimal contribution to prothrombinase complex, assuming its maximal activation, these observations would suggest some inherent advantage of platelet-released Factor $\mathrm{V}(\mathrm{Va})$ over that in the plasmatic environment of the platelet. Most likely, the recruitment and concentration of platelets to a site of vascular injury provides an excess of local platelet Factor Va receptor sites that require the release of the localized, stored platelet Factor V.

Studies are under way to characterize the structural abnormality of the apparent dysfunctional protein. Isolation of the abnormal Factor $\mathrm{V}$ from the patients' platelets, coupled with structure and function analyses, should begin to elucidate the nature of the defective molecule.

Studies are being performed to document more closely the natural history of the disease in the available family members. In line with the recommendations of the Subcommittee of Nomenclature of the International Society of Thrombosis and Hemostasis, we have named this qualitative disorder of Factor V, Factor V Quebec, as all the afflicted members of the family reside in that province of Canada.

\section{Acknowledgments}

We thank Sonia Singh for collecting the demographic data. We also thank Dr. Jacques Caen (Institut National de la Santé et de la Recherche Medicale, Hôpital Lariboisiere, Paris) for providing us with 
platelet lysates from a Gray platelet syndrome patient and a normal control for use in the Factor V RIA. Finally, we thank Stan Morton, Kathy Fluhrer, and Jeanne Nemitz for their assistance in the preparation of this manuscript.

This work was supported by a grant from the National Institutes of Health (HL-17430D), a National Institutes of Health Blood Banking and Hemostasis Training Grant (HL-07069) to Dr. Tracy, and by grants from the Medical Research Council of Canada (MA7667), the Ontario Ministry of Colleges and Universities, and the National Health and Research Development Program (Canada).

\section{References}

1. Davie, E. W., and K. Fujikawa. 1975. Basic mechanisms in blood coagulation. Ann. Rev. Biochem. 44:799-829.

2. Tracy, P. B., M. E. Nesheim, and K. G. Mann. 1981. Coordinate binding of factor $\mathrm{Va}$ and factor $\mathrm{Xa}$ to the unstimulated platelet. $J$. Biol. Chem. 256:743-751.

3. Kane, W. H., and P. W. Majerus. 1982. Interaction of human coagulation Factor Va with platelets. J. Biol. Chem. 257:3963-3969.

4. Nesheim, M. E., J. B. Taswell, and K. G. Mann. 1979. The contribution of bovine factor $\mathrm{V}$ and factor $\mathrm{Va}$ to the activity of prothrombinase. J. Biol. Chem. 254:10952-10962.

5. Suttie, J. W., and C. M. Jackson. 1977. Prothrombin structure, activation and biosynthesis. Physiol. Rev. 57:1-70. 156.

6. Mann, K. G. 1976. Prothrombin. Methods Enzymol. 45B:123-

7. Miletich, J. P., C. M. Jackson, and P. W. Majerus. 1978. Properties of the factor Xa binding sites on human platelets. J. Biol. Chem. 253:6908-6916.

8. Owren, P. A. 1947. Parahaemophilia, haemorrhagic diathesis due to the absence of a previously unknown clotting factor. Lancet. I:446-448.

9. Miletich, J. P., D. W. Majerus, and P. W. Majerus. 1978. Patients with congenital factor $\mathrm{V}$ deficiency have decreased factor $\mathrm{Xa}$ binding sites on their platelets. J. Clin. Invest. 62:824-832.

10. Katzmann, J. A., M. E. Nesheim, L. S. Hibbard, and K. G. Mann. 1981. Isolation of functional human coagulation factor $\mathrm{V}$ by using a hybridoma antibody. Proc. Natl. Acad. Sci. USA. 78:162-166.

11. Tracy, P. B., J. M. Peterson, M. E. Nesheim, F. C. McDuffie and K. G. Mann. 1979. Interaction of coagulation of factors $V$ and Va with platelets. J. Biol. Chem. 254:10354-10361.

12. Bajaj, S. P., S. I. Rapaport, and C. Prodanos. 1981. A simplified procedure for the purification of human prothrombin, factor IX and factor X. Prep. Biochem. 11:397-412.

13. Downing, M. R., R. J. Butkowski, M. M. Clark, and K. G. Mann. 1975. Human prothrombin activation. J. Biol. Chem. 250:88978906.

14. Kisiel, W., M. A. Hermodson, and E. W. Davie. 1976. Factor $X$ activating enzyme from Russell's viper venom: isolation and characterization. Biochemistry. 15:4901-4906.

15. Lundblad, R L., R. C. Uhteg, C. N. Vogel, H. S. Kingdon, and K. G. Mann. 1975. Preparation and partial characterization of two forms of bovine thrombin. Biochem. Biophys. Res. Commun. 66:482489.

16. Nesheim, M. E., F. G. Prendergast, and K. G. Mann. 1979. Interactions of a fluorescent active site-directed inhibitor of thrombin: dansylarginine N-(3-ethyl-1,5-pentanediyl)amide. Biochemistry. 18:9961003

17. Mustard, J. F., D. W. Perry, N. G. Ardlie, and M. A. Packham. 1972. Preparation of suspensions of washed platelets from humans. Br. J. Haematol. 22:193-204.

18. Proctor, R. R., and S. I. Rapaport. 1961. The partial thromboplastin time with kaolin; a simple screening test for first-stage plasma clotting factor deficiencies. Am. J. Clin. Path. 36:212-219.

19. Fletcher, A. P., N. Alkjaersig, and S. Sherry. 1959. The maintenance of a sustained thrombolytic state in man. I. Induction and effects. J. Clin. Invest. 38:1096-1110.

20. Zimmerman, T. S., O. D. Ratnoff, and A. S. Littell. 1971. Detection of carriers of classic hemophilia using an immunologic assay for anti-hemophilic factor (Factor VIII). J. Clin. Invest. 50:255-258.

21. Weiss, H. J., L. W. Hoyer, F. R. Rickles, A. Varma, and J. Rogers. 1973. Quantitative assay of plasma factor deficient in von Willebrand's disease that is necessary for platelet aggregation. Relationship to Factor VIII procoagulant activity and antigen content. J. Clin. Invest. 52:2708-2716.

22. Peak, I. R., A. L. Bloom, and J. C. Giddings. 1974. Inherited variants of factor VIII-related protein in von Willebrand's disease. New Engl. J. Med. 291:113-117.

23. Young, V. P., A. R. Giles, J. Pater, and W. E. N. Corbett. 1980. Sex differences in bleeding time and blood loss in normal subjects following aspirin ingestion. Thromb. Res. 20:705-709.

24. Nesheim, M. E., J. A. Katzmann, P. B. Tracy, and K. G. Mann. 1981. Factor V. Methods Enzymol. 80C:249-274.

25. Tracy, P. B., L. L. Eide, E. J. W. Bowie, and K. G. Mann. 1982. Radioimmunoassay of factor $\mathrm{V}$ in human plasma and platelets. Blood. 60:59-63.

26. Nesheim, M. E., K. H. Myrmel, L. S. Hibbard, and K. G. Mann. 1979. Isolation and characterization of single chain bovine factor V. J. Biol. Chem. 254:508-517.

27. Tracy, P. B., L. L. Eide, and K. G. Mann. 1983. Prothrombinase complex assembly on human platelets and peripheral blood leukocytes. Blood. 62(Suppl. 1):294a. (Abstr.)

28. Tracy, P. B., M. S. Rohrbach, and K. G. Mann. 1983. Functional prothrombinase complex assembly on isolated monocytes and lymphocytes. J. Biol. Chem. 258:7264-7267.

29. Giddings, J. C. 1981. Hereditary coagulation disorders: laboratory techniques. In Blood Coagulation and Hemostasis. J. M. Thomson, editor. Churchill-Livingstone, New York. 124.

30. Raccuglia, G. 1971. Gray platelet syndrome: a variety of qualitative platelet disorders. Am. J. Med. 51:818-828.

31. Ittyerah, T. R., R. Rawala, and R. W. Colman. 1981. Immunochemical studies of factor $\mathrm{V}$ in bovine platelets. Eur. J. Biochem. 120:235-241.

32. Chesney, C. M., D. Pifer, and R. W. Colman. 1981. Subcellular localization and secretion of factor $\mathrm{V}$ from human platelets. Proc. Natl. Acad. Sci. USA. 78:5180-5184.

33. Gerrard, J. M., D. R. Phillips, G. H. R. Rao, E. F. Plow, D. A. Walz, R. Ross, L. A. Harker, and J. G. White. 1980. Biochemical studies of two patients with the gray platelet syndrome. Selective deficiency of platelet alpha granules. J. Clin. Invest. 66:102-109.

34. Vicic, W. J., B. Lages, and H. J. Weiss. 1980. Release of human platelet factor $\mathrm{V}$ activity is induced by both collagen and ADP and is inhibited by aspirin. Blood. 56:448-455. 